\title{
Estado Novo no Brasil: Um Estudo da Dinâmica das Elites Políticas Regionais em Contexto Autoritário
}

\author{
Adriano Codato
}

Universidade Federal do Paraná (UFPR), Curitiba, PR, Brasil. E-mail: acodato@terra.com.br.

o Brasil, a passagem da hegemonia dos grupos políticos regionais
- as "oligarquias" - para a supremacia dos partidos nacionais foi uma operação longa e difícil. Essa ação, que ocorreu basicamente entre 1930 e 1945, exigiu hierarquizar, uniformizar e integrar os diversos grupos rivais das classes dirigentes, garantindo ao sistema político nacional três coisas: um grau razoável de coesão inter-regional (unidade), apoio contínuo ao presidente nacional (legitimidade) e equilíbrio institucional (governabilidade).

Esses 15 anos são, portanto, um momento excepcional para se perceber as diversas modificações operadas na estrutura da elite política brasileira. Não porque esta seja, em termos muito genéricos, "uma época de transformação social", e sim porque, nesse período, a questão da hierarquia no universo das elites tornou-se algo central na política brasileira. O interlúdio do Estado Novo (1937-1945), aliás, nunca fez nenhum mistério sobre isso: seus ideólogos anunciavam esses propósitos - "a expropriação política das potências privadas", para falar como Weber (1994) - como uma verdadeira política de Estado, tal qual as políticas industrial, trabalhista, cafeeira etc. A finalidade era "restaurar a autoridade nacional" (Vargas, 1938:23). É esse subperíodo, pouco analisado do ponto de vista da dinâmica especificamente política, que estudaremos aqui ${ }^{1}$. O objetivo deste artigo é explicar a lógica política subjacente à política de Getúlio Vargas para lidar com as oligarquias regionais no pós-1937.

DADOS - Revista de Ciências Sociais, Rio de Janeiro, vol. 58, n-2, 2015, pp. 305 a 330. 


\section{Adriano Codato}

Como se recorda, em 10 de novembro de 1937 o presidente dos Estados Unidos do Brasil anunciou, pelo rádio, a decretação de uma nova Constituição. Junto com este ato, foram fechadas as Casas Legislativas do país: câmaras de vereadores, assembleias estaduais, câmara federal e senado da República. Os mandatos dos parlamentares foram cassados e as eleições presidenciais, programadas para o começo de 1938, foram canceladas. Os governadores dos estados foram destituídos e em seus lugares foram nomeados "interventores federais". No início de dezembro de 1937, todos os partidos políticos e milícias cívicas foram extintos (Decreto-Lei no 37 ).

Essa nova realidade pôs três problemas para o novo regime: i) como organizar a representação política regional, de maneira a permitir a expressão, ainda que de forma controlada, das várias correntes políticas oligárquicas sem aumentar o grau de conflito no interior do sistema e sem restituir completamente suas importâncias respectivas?; ii) como remontar uma estrutura administrativa impedindo que o interventor (indicado pelo presidente) formasse sua própria clientela (junto aos prefeitos municipais, por exemplo) e constituísse um "partido" estadual em oposição aberta ou velada ao próprio presidente?; e, por fim, iii) como garantir, para o "chefe político nacional", na expressão do regime, o poder arbitral e inconteste entre os interventores federais e as elites estaduais?

Menos de dois anos após o golpe de Estado, em abril de 1939, Getúlio Vargas instituiu, em cada um dos estados, um "departamento administrativo" 2 . Compostos por um número variável de quatro a dez integrantes, esses departamentos deveriam aprovar ou recusar os decretos-lei baixados pelo interventor. Esse sistema de governo que somava Interventoria e Departamento Administrativo substituía, formalmente, o Executivo e o Legislativo estaduais ${ }^{3}$. O propósito do presidente, que escolhia e nomeava livremente tanto os interventores quanto os conselheiros desses departamentos, foi dotar o sistema político de um mecanismo de contrapeso ao poder dos interventores, no qual ele próprio surgisse como o árbitro final das disputas intrarregionais. Aqueles três problemas mencionados anteriormente - a representação das várias facções estaduais, o controle estrito dos interventores e a supervisão constante do presidente da República sobre a política regional-foram, em princípio, solucionados assim.

Contudo, permanece uma questão: quais os critérios ou quais os cálculos políticos que orientam a nomeação dos ocupantes das cadeiras do 
Departamento Administrativo do estado e dos interventores federais? Para responder a essa questão, examinam-se os princípios políticos de seleção da nova classe política que vigoraram em São Paulo entre 1937 e 1947.

É provável que o caso paulista, em função de todas as questões específicas que envolvem (a força dos partidos oligárquicos, a influência nacional das lideranças políticas estaduais, o conflito aberto com o governo federal em 1932, o monopólio da produção do café etc.), não seja representativo da lógica que comanda esse processo de circulação de elites de cada estado da Federação. Ainda assim, o interesse em estudá-lo deriva do fato dele ser um caso-limite em que as ocorrências do problema são mais intensas - um "exemplo dramático", por assim dizer".

Na seção seguinte, apresenta-se os integrantes dessa "nova" elite paulista. É mostrado ano a ano a formação do Departamento Administrativo de São Paulo (Daesp) e a sequência de interventores no estado. O ponto mais notável aqui é a filiação antivarguista de todos os seus integrantes. Na segunda e na terceira seções procura-se compreender e explicar como essa classe governante é constituída - não os princípios legais dessa constituição, mas sua coerência política. Avançamos neste artigo duas ideias: 1) a de geometria variável, para caracterizar a inconstância desse sistema de relações políticas e as mais variadas conexões entre, de um lado, a elite que comanda o Estado nacional e as elites políticas regionais e, de outro, as ligações cambiantes entre as próprias facções das elites regionais; e 2) a ideia de personalismo institucionalizado. Esse personalismo não se confunde com o arbítrio pessoal do ditador: ainda que a arquitetura administrativa e a ideologia autoritária do Estado Novo prevejam a concentração do poder de decidir no chefe político nacional, ele mesmo se vê condicionado pelos contextos políticos sobre os quais age e pelas regras e instituições de um governo burocrático. Nas considerações finais, avalia-se a amplitude desse processo de circulação de elites e discute-se a validade ou não da noção usual empregada pela literatura para descrever esse fenômeno de acomodações sucessivas entre as elites no poder: "cooptação".

Antes, são necessárias algumas notas sobre as fontes históricas e o seu tratamento.

Muito embora o grande volume de documentação disponível hoje (arquivos privados, correspondências pessoais, documentos oficiais, dis- 
cursos de autoridades, relatórios de governos, depoimentos de protagonistas etc.) trate quase exclusivamente das disputas políticas intrarregionais e inter-regionais, praticamente inexistem estudos sobre os políticos profissionais desse período ou sobre as relações entre Getúlio Vargas e a "oligarquia paulista", como se poderia esperar ${ }^{5}$. Os agentes políticos são tema de dois tipos de trabalhos: biografias, memórias e autobiografias, ou estudos focados em acontecimentos, motivos e propósitos. Nesses casos, o que conta são os feitos e os fatos da história de um indivíduo, mais que a estrutura política na qual estão inseridos. Essa ocorrência na literatura se deve menos a opções teóricas e mais à metodologia dos estudos e à natureza "factual" das fontes ${ }^{6}$.

Por outro lado, trata-se aqui de pensar a história política desse período não a partir das relações interpessoais entre o ditador e os oligarcas, e sim numa perspectiva mais sociológica, como relações entre um grupo de elite nacional e outro, regional. Essas relações podem também ser percebidas como relações interinstitucionais, isto é, entre instituições políticas federais e estaduais, na crença de que estudos de elites funcionam, conforme Robert D. Putnam indicou, "como uma espécie de sismógrafo para detectar mudanças políticas mais profundas" (1976:43).

\section{O PESSOAL POLÍTICO-ADMINISTRATIVO DO ESTADO NOVO}

Após o golpe de 10 de novembro de 1937, abolida a Constituição de 1934 e decretado o Estado Novo, o presidente da República tornou-se todo-poderoso. Entre os lances à disposição do ditador estavam incluídos aqueles cujas regras ele mesmo determinava, e sua jogada mais inspirada consistiu em submeter a elite política à sua política pessoal servindo-se dos quadros provenientes da própria elite. Explico.

A coerência das sucessivas nomeações para as interventorias federais ou para os departamentos administrativos deveria orientar-se menos por preferências pessoais e mais pelos fins que se desejava alcançar. Em termos abstratos, estabilidade institucional, legitimidade política e "unificação do Estado nacional" (isto é, a integração social e econômica dos subsistemas regionais e sua submissão ao Catete). Em termos mais específicos, as indicações para os cargos estaduais estavam sujeitas às intenções de enquadrar política e administrativamente a oligarquia.

Aparentemente, valia para os interventores o mesmo preceito que, de acordo com Carone, estava em vigor para a composição dos ministérios: "a ação política de Getúlio Vargas" não se caracteriza por princí- 
pios ideológicos definitivos, mas "pelo jogo de equilíbrio de forças - o que lhe permite atuar segundo suas conveniências" (Carone, 1976:264). No caso específico das interventorias, as escolhas seguiam, em geral, três critérios diferentes, mas sempre adaptados sejam às conveniências federais sejam às circunstâncias políticas locais.

A escalação do governante poderia recair "num elemento estranho ao estado", sem ligações com a oligarquia, ou seja, um outsider. Foi o caso do Rio Grande do Sul (general Daltro Filho), da Bahia (Juraci Magalhães), do Rio de Janeiro (Amaral Peixoto), do Paraná (Manoel Ribas) e de Goiás (Pedro Ludovico). Uma alternativa também muito utilizada pelo regime era a seguinte: o indicado seria já um "elemento do estado"; todavia, ele deveria ser uma figura menor e menos importante dos partidos reinantes na cena política local. Benedito Valadares, em Minas Gerais, e Ademar de Barros, em São Paulo, são exemplos típicos dessa política aparentemente errática. Por fim, a instituição do interventor federal nos estados menores e/ ou menos problemáticos poderia recair "em elemento da oligarquia dominante do estado", como Nereu Ramos em Santa Catarina (Carone, 1976:151; Codato, 2013). Em comum em todas essas escolhas era a lealdade pessoal que os nominados passavam a dever a quem os nomeou.

Todavia, um sistema de governo baseado exclusivamente nas interventorias federais mostrou-se pouco eficaz para o tamanho da tarefa a que o regime se propunha. Ao fechar os parlamentos, eliminar o sufrágio universal e os direitos individuais, os direitos políticos e a liberdade de imprensa e, posteriormente, tornar ilegais os partidos, reduziram-se nesse movimento não somente as bases de apoio do regime, mas também os canais de vocalização de interesses, fazendo do sistema político uma estrutura rígida e inflexível. Assim, mesmo controlando os interventores e tendo a expectativa de, por meio deles, controlar os prefeitos municipais, ainda restava o problema: o que fazer com todos os outros "carcomidos"?

Sem que seja preciso descrever a sucessão dos muitos órgãos políticos, aparelhos burocráticos e posições institucionais do regime ditatorial, a limitação das autonomias regionais pode ser compreendida quando se tem em mente os mecanismos de enquadramento e harmonização das elites regionais. Entre eles estão os departamentos administrativos.

Vejamos o caso do departamento de São Paulo. Ele deve permitir apreender o sucesso de um filtro institucional que combinou certo grau de 


\section{Adriano Codato}

abertura a alguns indivíduos, com determinadas exigências políticas dirigidas aos velhos grupos políticos remanescentes da República Oligárquica.

O art. 13 do Decreto-Lei no 1.202/1939 havia estipulado que cada departamento seria "constituído de 4 a 10 membros". Na prática, esse número variou bastante, e nenhum estado chegou a contar com mais de sete integrantes. O total de conselheiros divergia de acordo com a importância econômica do estado, o tipo de conflito político que Getúlio Vargas deveria enfrentar e o grau de intriga pessoal entre as várias facções da oligarquia local. São Paulo, Minas Gerais e Rio Grande do Sul ficaram com sete membros cada; Rio de Janeiro, Bahia, Pernambuco, Ceará e Pará, cinco; os demais estados, quatro ${ }^{8}$.

Esses indicados deveriam ser brasileiros natos e maiores de 25 anos, sendo "nomeados pelo presidente da República", e não pelo interventor. $\mathrm{O}$ art. 14 fixava algumas restrições importantes à regra geral. As indicações não poderiam recair em quem tivesse contato direto ou contrato com a administração pública federal, estadual ou municipal, fosse funcionário público estadual ou municipal (caso dos professores, por exemplo, exceto se estivessem em disponibilidade), fosse proprietário de empresa concessionária de serviço público, recebesse rendimentos "do poder público" ou embolsasse, a qualquer título, remuneração de empresas que prestassem serviços ao governo, orientação que, na prática, afastava os empreendedores que faziam ou desejavam fazer negócios com o Estado. As consequências dessa disposição foram barrar intelectuais financiados pelo governo e também demover empresários privados e dirigentes de associações de classe, reforçando a opção não pelos técnicos (Lowenstein, 1944; Graham, 1968), mas pelos políticos profissionais, justamente aqueles que deveriam ser, em nome da racionalidade da administração e do espírito de união nacional, evitados. Horácio Lafer, designado em junho de 1939 para integrar o departamento paulista aparentemente sem ser consultado, escreveu ao ministro da Justiça Francisco Campos dois dias depois alegando outras ocupações e solicitou a nomeação de um substituto ${ }^{9}$. Nesses casos, o ministro declarava "sem efeito" as indicações e imediatamente conduzia aos cargos outros colaboradores ${ }^{10}$.

Tendo presentes essas orientações formais e esses limites burocráticos, no caso da unidade mais problemática do país, quem compôs o departamento administrativo de São Paulo? O Quadro 1, a seguir, apresenta 
Estado Novo no Brasil

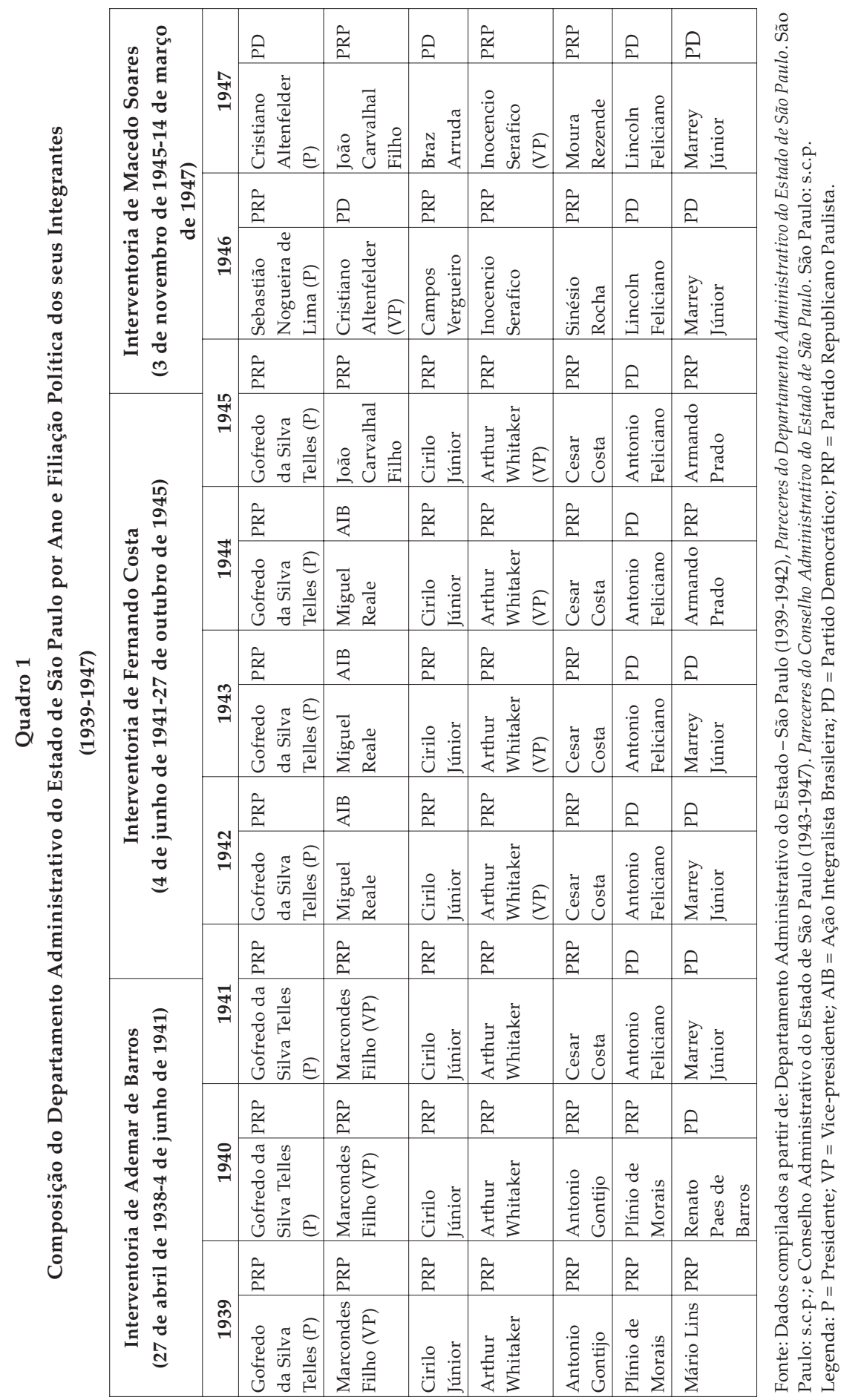

DADOS - Revista de Ciências Sociais, Rio de Janeiro, vol. 58, nํㅡ 2, 2015 
ano a ano a formação política do departamento paulista. O Daesp, formado por sete membros (número máximo estipulado), possuía um presidente e seis conselheiros, sendo um deles também o seu vicepresidente.

Dessa simples relação de nomes e das sucessivas substituições durante o longo intervalo em que esse aparelho esteve ativo (nove anos), podem-se extrair algumas constatações.

Se durante o período do Estado Novo o departamento de São Paulo foi administrado pelos perrepistas, ninguém menos que os inimigos da revolução que conduziu Vargas ao poder em 1930, serão os democráticos, os amigos da revolução, que lotearão entre si as sete cadeiras do Daesp depois do golpe de Estado que em 1945 irá depor Vargas e porá fim ao período revolucionário que ambos iniciaram em 1930. O registro inflamado do jornalista Lourival Coutinho capta o essencial e o paradoxal dessa situação. Uma inspeção no Quadro 1 permite ver que "alguns [...] elementos de proa, solidários com o movimento paulista [de 1932], vieram a ser, mais tarde, magnificentes servidores do governo do Sr. Getúlio Vargas e [justamente] quando esse governo se mostrou mais reacionário e mais liberticida, na insânia do Estado Novo" (Coutinho, 1955:188).

Prova da afirmação anterior: Antonio Feliciano e Marrey Júnior firmaram em fevereiro de 1932 o Manifesto do Partido Democrático contra o governo provisório de Getúlio Vargas (1930-1934); Arthur Whitaker, Marcondes Filho e Cirilo Júnior, em janeiro do mesmo ano, já haviam assinado o Manifesto do Partido Republicano Paulista contra a nomeação de "estrangeiros" (i.e., não paulistas) para dirigir o estado; os três primeiros assinaram o documento de formação da Frente Única Paulista, organização que unificou os dois partidos da oligarquia e que levou ao levante contra a União em julho de 1932. Miguel Reale foi para frente de batalha na Revolução paulista em 1932 como terceiro sargento e logo depois se filiou à Ação Integralista Brasileira, que em 1938 tentou assassinar o presidente. Engrossaram ainda as fileiras da Frente Única Paulista Gofredo da Silva Telles, João Carvalhal Filho e Plínio de Moraes - este, membro da Comissão do MMDC (movimento cívico estadual) e tido como herói da guerra de 1932. Cirilo Júnior, Marrey Júnior e Gofredo Telles (esse último, prefeito nomeado de São Paulo durante o movimento insurrecional) foram presos a mando de Vargas após o levante. Gofredo foi para o exílio na França e Cirilo foi deporta- 
do para Portugal. Em resumo: Getúlio Vargas acomodou nas duas posições políticas mais importantes do estado-departamento e interventoria - os políticos de carreira do Partido Republicano Paulista (PRP) que haviam sido destituídos em 1930, combatido pelas armas seu governo em 1932 e se oposto ao golpe do Estado Novo em 1937. Que lógica guiou essas indicações?

\section{A GEOMETRIA VARIÁVEL DAS RELAÇÕES POLÍTICAS}

A inconstância das relações entre Vargas e seus inimigos do PRP (ou com seus ex-amigos do Partido Democrático) possui algumas especificidades. Olhadas de perto, elas são condicionadas por três fatores, ora mais institucionais, ora mais sociais:

1) as transformações do regime ditatorial (suas crises políticas);

2) as múltiplas combinações, modificáveis conforme as circunstâncias, entre as facções das elites regionais (a dinâmica intraelite); e

3) os ajustes entre as elites regionais e a elite nacional (a dinâmica interelite).

Os arranjos possíveis entre esses três fatores - modificáveis de estado para estado, de elite para elite, ou a cada conjuntura crítica entre 1930 e 1945 - permitem compreender o principal traço desse sistema de relações políticas, a que chamarei de geometria variável. Essa matemática obedece menos às "artes da política" ou ao "maquiavelismo" presidencial (no sentido pejorativo do termo), e mais àquilo que comanda esse sistema político como um todo: o personalismo institucionalizado. Esse será tratado em detalhes na próxima seção.

Conforme as transformações do próprio regime ditatorial, o Daesp teve três fases: i) a fase da interventoria de Ademar de Barros, até junho de 1941; ii) a fase da interventoria de Fernando Costa, que vai até o fim do regime do Estado Novo, quando o Decreto-Lei no 8.219 extinguiu os departamentos administrativos em novembro de 1945; e iii) a última fase, de interventoria de Macedo Soares, após o Decreto-Lei no 8.974, que restaurou os departamentos administrativos no início de 1946 medida adotada para preencher o vazio que se constatou no sistema decisório com a ausência das assembleias legislativas estaduais, que ainda não haviam sido recriadas. Cada fase dessas correspondeu a um desenho das forças políticas bem determinado. As grandes modificações na formação do departamento paulista coincidiram justamente com crises políticas e com as substituições dos interventores federais.

DADOS - Revista de Ciências Sociais, Rio de Janeiro, vol. 58, noำ 2, 2015 
Em 1941, depois da demissão de Ademar de Barros, metade dos conselheiros foi trocada. Entraram: Cesar Costa, Antonio Feliciano e Marrey Júnior, todos em 18 de junho, duas semanas após a posse do novo nomeado, Fernando Costa. Quando o Daesp é recriado em 1946, tendo já na chefia do governo Macedo Soares, sua formação é totalmente diferente em relação àquela que terminara junto com o Estado Novo. Mas agora, se todos eram antigos na política estadual, a maioria (exceto Marrey Júnior) era nova na Casa. Esse paralelismo indica que a dinâmica interna do aparelho dependia diretamente da dinâmica de poder do próprio regime, da sua evolução institucional e da sua transformação política, proposição que exclui, de saída, quaisquer explicações focadas apenas na vida íntima da agência e na história administrativa do governo.

Já as pequenas modificações na composição da agência resultavam de acomodações e acordos internos ao universo da elite e eram motivadas, em geral, pela circulação dos indivíduos pelos aparelhos políticos do Estado ditatorial. Tanto é assim que durante a interventoria de Ademar a única alteração que ocorre, em 1940, é resultado de uma promoção: Renato Paes de Barros (integrante do Conselho Técnico de Economia e Finanças do Estado) foi indicado para a vaga de Mário Lins quando este se tornou o secretário da Educação e Saúde Pública do governo do estado. Na interventoria de Fernando Costa, Antonio Gontijo deixou o Daesp em 18 de junho 1941 para assumir a Comissão de Negócios do Estado, cargo que acumulou parcialmente com a presidência da subcomissão de Organização e Finanças do Estado. Em seu lugar foi nomeado Cesar Costa. Antonio Feliciano substituiu Plínio de Moraes e Marrey Júnior substituiu Renato Paes de Barros também na série de modificações do dia 18 de junho ${ }^{11}$. No fim do ano, a convite de Vargas, o perrepista Marcondes Filho assumiu o Ministério do Trabalho, Indústria e Comércio e cedeu sua cadeira ao integralista Miguel Reale ${ }^{12}$. Em 1944, Armando Prado é empossado no Daesp no lugar de Marrey Júnior quando esse último torna-se secretário da Justiça e Negócios Interiores de Fernando Costa. Somente em março de 1945 há uma substituição cuja motivação é resultado direto de um conflito ideológico com o regime: Miguel Reale rompe publicamente com o Estado Novo, renuncia ao posto e é substituído por João Carvalhal Filho ${ }^{13}$. Em 1947 há mais uma renovação considerável: entram dois novos membros (Moura Rezende e Braz Arruda), um retorna (João Carvalhal Filho) e Cristiano Altenfelder torna-se o presidente do Departamento paulista. Essas alterações não dizem respeito nem à conjuntura eleitoral, nem 
refletem a busca, por parte dos conselheiros, de uma carreira parlamentar, com a reabertura das assembleias legislativas e câmaras de vereadores. Sinésio Rocha torna-se secretário de Estado e Sebastião Nogueira de Lima e Campos Vergueiro transferem-se para o Tribunal de Contas de São Paulo.

O aspecto fundamental nem é tanto a circulação interaparelhos, ou em que ritmo as substituições se dão, mas por que exatamente entram e saem esses indivíduos e não outros quaisquer? Aqui o que conta é aquele terceiro fator mencionado anteriormente: as combinações entre as elites regionais e a elite nacional ou a dinâmica interelite.

A escolha dos titulares do departamento administrativo de São Paulo dependia de uma geometria variável, e muitas vezes ad hoc, que fosse capaz de combinar sejam as aspirações do presidente em redefinir aliados e recompor suas bases políticas (as "situações") nos estados mais problemáticos, como São Paulo e Rio Grande do Sul, por exemplo; sejam as pressões dos interventores para emplacar seus afilhados políticos ou alguém de sua área de influência desde que tiveram de assimilar a existência desse Departamento, que deveria avaliar suas decisões; sejam ainda os propósitos do regime que deveria literalmente inventar, por delegação, uma elite política sediada nos Departamentos que, através das funções de fiscalização sobre o interventor que estava incumbida de exercer, deveria impedir o nascimento de lideranças políticas regionais que se destacassem do controle estrito pretendido pelo presidente. Caso descontássemos o tom ufanista no qual a oração foi pronunciada, ela diria mais ou menos o mesmo: "Tão multiformes eram as correntes" políticas nos estados que Vargas "se via obrigado a jogar, como certos campeões de xadrez, em numerosos tabuleiros ao mesmo tempo, e a vencer em todos eles, se não quisesse ver o seu País, e a si mesmo, perdidos" (Frischauer, 1943:332).

Nesse contexto, os interesses políticos de todas as partes envolvidas decidem tanto a configuração quanto a evolução burocrática do sistema ditatorial, evolução e configuração estas que expõem a luta, ora aberta ora velada, entre a elite nativa que habita o departamento administrativo, o preposto federal que governa a interventoria e o comandante nacional que manda em todos e em tudo ao mesmo tempo.

A propósito, a história da nomeação de Reale, um dos chefes do integralismo nacional, é por si só um exemplo muito ilustrativo desse jogo de pressões e contrapressões entre presidente, interventor e oligarquia 


\section{Adriano Codato}

e do cálculo político do primeiro para sustentar o equilíbrio (ou o "Estado de compromisso") entre as forças políticas estaduais em benefício da sua ditadura. Tendo presente essa ideia de geometria variável e conhecendo um pouco o dia a dia da política paulista, a escolha de nomes para integrar a agência deve parecer menos casual.

Fernando Costa assumiu a interventoria em São Paulo em meados de 1941. O fato contemplava os desejos dos perrepistas, que não aturavam mais Ademar de Barros, sua corriola própria de prefeitos, seus "desmandos" e seus trambiques financeiros ${ }^{14}$. Logo no ano seguinte, o presidente Vargas decide promover Alexandre Marcondes Filho a ministro do Trabalho, Indústria e Comércio e convidar o integralista Miguel Reale para o Daesp ${ }^{15}$. O diálogo entre os dois, relatado pelo próprio Reale:

Getúlio: - "Preciso de sangue novo em São Paulo, com pessoa que traga ideias novas ao regime. Conto com sua colaboração". Não vacilei um instante sequer, pois em meu ser sempre atuaram duas valências, uma jurídica, outra política, ambas em busca de sincronia. Aceitando o convite, indaguei se o Interventor Fernando Costa ou o presidente do Departamento [Gofredo Telles] estavam a par de meu ingresso em órgão tão relevante na vida administrativa de meu estado. Foi então que notei a veia humorística de Getúlio Vargas, o qual, após uma baforada de charuto que o não largava, indagou: - "Para quê? Na minha terra costuma-se dizer que se deve encostar o relho ora no burro, ora na cangalha, para o burro saber que tem dono..." (1986:164).

Se a admoestação a uns e a eleição de outro for percebida apenas como capricho do ditador, a narrativa ganha em curiosidade histórica, mas perde seu sentido político - e sua função como chave para ilustrar a sócio-lógica desse sistema e sua forma aparentemente errática de obter apoio e consentimento.

Outras evidências, se não comprovam a ideia da geometria variável entre as forças políticas em presença, vão na mesma direção. A formação inicial de três outros departamentos administrativos - do Rio Grande do Sul, de Minas Gerais e do Paraná - revela que suas matemáticas respectivas adaptavam-se às situações políticas regionais, mantendo o princípio do pluralismo limitado no universo das elites.

Abreu constata, com base na filiação partidária de cada conselheiro do Rio Grande do Sul, que, assim como todo o secretariado do governo, o 
departamento administrativo gaúcho "foi dividido equitativamente entre os representantes dos diferentes grupos regionais - Partido Republicano Liberal, Partido Libertador e dissidência liberal" (Abreu, 2007:215). Portanto, parece-me francamente exagerada a opinião de Dilan Camargo, para quem a indicação, embora coubesse legalmente ao presidente da República, "de fato pertencia às forças políticas do estado, em concordância com o Interventor federal" do Rio Grande do Sul (Camargo, 1983:117). Dependendo do caso, a influência do Interventor poderia ser maior ou menor. Dantas garante, ainda que não forneça prova empírica alguma, que o departamento administrativo em Sergipe tinha todos os seus membros "indicados pelo Interventor entre o pessoal de sua confiança" (1982:194). Ao menos no Paraná, para contrabalançar a presença e a ingerência de um interventor "estrangeiro" (Manoel Ribas fizera carreira no Rio Grande do Sul), nomeou-se para o Departamento, num primeiro momento, a fina flor do Partido Republicano Paranaense ${ }^{16}$. Já em Minas Gerais, Benedito Valadares emplacou sua turma: dos sete titulares do departamento administrativo do estado de Minas Gerais (DAE-MG), cinco eram seus aliados ${ }^{17}$.

\section{O PERSONALISMO INSTITUCIONALIZADO E O SISTEMA POLÍTICO DITATORIAL}

Pelo exposto até aqui, é possível afirmar que o perfil dos conselheiros escolhidos para o departamento administrativo não é consequência da clarividência presidencial, do gênio maquiavélico ou da eleição idiossincrática de favoritos e protegidos, muito menos o resultado daquilo que Bourdieu chamou de "narcisismo de instituição": a prerrogativa que o governante possui de confundir "os recursos ou os interesses da instituição" estatal "e os recursos e os interesses da pessoa" que encarna a instituição estatal (2005:59). Sob o regime do Estado Novo, esse princípio - o patrimonialismo - adquire uma feição própria e cede lugar a um procedimento de governo baseado no personalismo, sinônimo aqui de poder pessoal excessivo ou absoluto. Esse segundo princípio - o personalismo - deve ser compreendido em toda sua complexidade: seja pela forma (ideológica) como é justificado, seja pela maneira formal (administrativa) como se explicita praticamente nesse contexto institucional.

Os artigos 3e e 13ㅇ do Decreto-Lei 1.202 (“O interventor será nomeado pelo Presidente da República”; "Os membros do Departamento Administrativo serão nomeados pelo Presidente da República") ilustram 


\section{Adriano Codato}

e realizam, na prática, aquilo que a doutrina autoritária previa através de sua retórica grandiloquente: Getúlio Vargas, o indivíduo em carne e osso, torna-se, com o regime do Estado Novo, não o simples executor de um mandato representativo, mas o "Chefe da Nação" (a expressão é de Azevedo Amaral, 1938), o "Cesar temporário" (conforme Francisco Campos, 1940b), ou, ainda, a encarnação física do "Estado Moderno" (segundo Oliveira Vianna, 1974). Esses vários jeitos de decretar o princípio absolutista de "O Estado sou eu" - visto que "Presidente da República" é, naquelas sentenças legais do decreto-lei, uma antonomásia - não tem a ver com a embrulhada entre a esfera pública e a esfera privada, ou com a sobreposição, típica do Estado dinástico, entre a posição e o seu ocupante (por oposição à separação, legal e real, entre função e funcionário, que é a essência do Estado burocrático). $\mathrm{O}$ "absolutismo" que caracteriza esse sistema de governo com Vargas à frente deriva das transformações que ocorrem nesse período: a mudança da forma de regime e da fórmula política ${ }^{18}$ que a acompanha e explica.

Uma maneira direta e didática de captar as reviravoltas do princípio de legitimidade do poder de Estado (problema este que está ligado tanto à forma de investimento do soberano no poder quanto ao poder do soberano de investir em seus representantes) e entender o alcance da ideia do que chamei de personalismo institucionalizado (e sua diferença em relação ao "narcisismo institucional" de Bourdieu) é acompanhar a lição de Azevedo Amaral:

A velha democracia liberal tinha como uma de suas características principais o regime do anonimato, que se estendia a todos os setores da organização estatal [...]. Daí a fisionomia acentuadamente impessoal daquele sistema e a irresponsabilidade que desse impersonalismo promanava, imprimindo ao aparelho político a forma de um maquinismo cujas engrenagens funcionavam movidas por uma força inconsciente, em obediência a princípios teóricos abstratos. Em todo o funcionamento dessa maquinaria, não se podia distinguir a influência de elementos humanos e a intervenção de uma vontade individualizada. Nas organizações estatais do tipo novo, como tão nitidamente se patenteia no caso brasileiro, depara-se-nos precisamente o contrário desse anonimato [...]. Na democracia nova [isto é, no regime ditatorial] os preceitos [liberais] cedem lugar à ação constante da personalidade do estadista que [...] contenta-se em formular certas regras, derivadas da experiência do poder, mas que na prática do governo e na elaboração das leis resolve cada 
caso concreto com espírito de realismo e objetividade. [...] Um regime como o que foi instituído no Brasil pela Constituição de 10 de novembro é, portanto, um sistema de governo essencialmente humano. O poder pessoal, que as ficções do liberalismo democrático depreciaram [...], ressurge como elemento básico e insubstituível na direção das atividades do Estado e no encaminhamento da marcha progressiva da Nação (Amaral, 1943:35; ênfases minhas).

Essa ladainha secular, recitada à exaustão por todos os sábios do período, confunde de maneira proposital a vontade pessoal do presidente (o indivíduo empírico) com a vontade geral da Nação (a entidade abstrata), e assume que aquele não só é a manifestação terrena desta, como também seu único veículo. Portanto, para todos os efeitos,

$$
\text { Povo }=\text { Presidente }=\text { Getúlio Vargas }(\text { a pessoa })
$$

Segundo essa equação, livre dos artifícios do "demoliberalismo", neologismo que Francisco Campos maquinou para desqualificar a liberal-democracia, o "povo representa o Estado sob a forma da pessoa humana", e não através de símbolos políticos abstratos e esquemas jurídicos etéreos, como no regime da Constituição de 1891. Esse Estado, "dotado de vontade e de virtudes humanas", só "se torna visível e sensível", isto é, só existe e pode existir através do Chefe. É ele quem deve interpretar a ambição do povo, decidir por ele e assumir a responsabilidade pelas decisões, já que o soberano encarna em si próprio ou personaliza a ideia de soberania (Campos, 1940a:211-213). Portanto,

$$
\text { Estado }=\text { Chefe }(\text { Getúlio Vargas })=\text { Povo }
$$

Nesse contexto, e segundo essa dieta, não há como dissociar o personalismo (e o seu correlato, o poder solitário de escolher) da instituição (um conjunto de regras impessoais e aparelhos públicos encarregados do processo de governo). Não porque a instituição - a instituição "Departamento Administrativo" ou a "Interventoria Federal" - seja uma extensão da vontade individual do Chefe e uma prova a mais do narcisismo que anima todo o sistema ditatorial, e sim porque é o personalismo que põe em movimento o sistema político-institucional, este sistema, neste contexto político, nesse momento histórico, e o faz funcionar. Sua operação, todavia, nunca é em benefício do chefe da Nação, nem sua relação com as instituições políticas é uma relação patrimonialista 


\section{Adriano Codato}

- peculiaridade dessa forma de regime que permite ser despótico sem por isso tirar proveito material da situação política.

Oliveira Vianna sublinha que é esse, justamente, o espírito e o significado do art. 73 da Carta de $37^{19}$ : ele "deu ao Presidente da República a prerrogativa de dirigir a política administrativa e legislativa da União - e está certo; é este - o político - justamente o domínio dos homens de Estado". Problema diferente, todavia, da competência técnica para administrar e legislar. Vianna se apressa em emendar que "O texto do artigo 73 não permite, nem autoriza, a extravagante interpretação de que, em matéria de legislação ou de administração, o Presidente deve ser o autor de tudo" (Vianna, 1974).

O que chamei então de personalismo institucionalizado é, afinal, a condição de realização prática do sistema político ditatorial e, ao mesmo tempo, a maneira pela qual o poder "pessoal" se exprime e se explica. A liberdade de escolha dos membros da elite, destituídos dos meios de sua própria seleção e dependentes diretos do aval da liderança nacional autoritária, está, no entanto, condicionada pela lógica mais geral desse universo político, e seu sintoma é, justamente, a geometria variável que o presidente Getúlio Vargas pode manipular, mas que precisa, também, acompanhar. Paradoxalmente, no curso desse processo de arregimentação de lealdades e de confirmação de apoios, aquele mesmo que faz as regras e fixa as diretrizes da organização - o presidente deve, em nome da eficiência política e administrativa do sistema, submeter-se a elas depois ${ }^{20}$.

Se o propósito do governo central era mais ambicioso - reordenar as hierarquias políticas estaduais (portanto, mais do que simplesmente "controlar o interventor") -, nada mais esperável que o placar do departamento administrativo assinalasse sempre um número menor de aliados do interventor e uns poucos indivíduos indicados graças à sua influência.

Assumindo, por hipótese, que a impressão de Miguel Reale sobre o presidente do "daspinho" de São Paulo fosse correta (o doutor Gofredo da Silva Telles teria sido "sempre arredio às vicissitudes do Palácio do Governo" (Reale, 1986:169)), e que ela valesse tanto para Ademar, quanto para Fernando Costa, deve-se recordar que, quando o Departamento foi criado em 1939, Ademar, que era de uma ala mais jovem e de menor prestígio do PRP, só podia contar com o concurso de dois ou três 
membros, no máximo. Ele podia estar certo do apoio do coronel Mário Lins (que só foi indicado graças à desistência de Horácio Lafer ${ }^{21}$ ) e Plínio de Moraes, político de interior. Os outros integrantes eram não só mais velhos ou de outra geração política (Ademar tinha apenas 37 anos de idade em 1938), mas de outra ala do PRP, mais tradicional e mais oligárquica. Ao longo do tempo e graças a alguns negócios em comum, o interventor trouxe para sua banda Cirilo Júnior, seu ex-colega de bancada na Assembleia Legislativa, mas nem sempre simpático a suas posições e pronunciamentos ${ }^{22}$. Quando Fernando Costa assumiu (em 1941), houve três substituições no Daesp e os novos indicados podiam ser agora cotados, conforme a geometria variável de alianças, como homens ligados a Ademar ${ }^{23}$. Invertia-se o jogo, portanto. A saída de Marcondes Filho e a escolha de Miguel Reale não melhoraram em nada a situação para o interventor recém-nomeado, que de fato só pôde receber algum reforço no momento em que Armando Prado substituiu Marrey Júnior (promovido a secretário de Estado e integrado a seu governo em 1944) e João Carvalhal Filho sucedeu Miguel Reale, porque este resolveu, por conta própria, demitir-se em 1945.

\section{CONSIDERAÇÕES FINAIS}

Quando se examina mais de perto a sorte das classes dirigentes regionais entre as deposições de Washington Luís (1930) e Getúlio Vargas (1945), o que se constata é que não há nem substituição de um grupo político por outro completamente diferente; nem reordenação dos mesmos grupos num universo extremamente fechado; nem depuração, através de sucessivos expurgos políticos irreversíveis, das elites. O que há é um movimento de conservação parcial do pessoal político, o que também significa renovação parcial desse pessoal.

A recomposição dos quadros dirigentes é controlada por um mecanismo político-institucional que tem na Interventoria Federal e no Departamento Administrativo seus principais exemplos. O princípio de indicação superior permite substituições gradativas de alguns nomes, sem eliminar todos os grupos ou afetar muitos interesses estabelecidos de uma só vez, aspecto que escapa à tese da "substituição das elites no pós-30".

Esse artifício bastante seletivo de conservação e renovação (Camargo, A., 1983:38-39), dirigido desde cima pelo presidente da República por meio de uma hábil política de destituições, acomodações e reabilitações, foi percebida por vários autores como "cooptação" (Miceli, 


\section{Adriano Codato}

2001:243-244). Contudo, pelos exemplos que tratamos aqui, o mais apropriado para descrever esse processo não seria a ideia de cooptação, mas a de transformismo da elite política.

A noção de cooptação supõe um processo em grande medida intencional de aliciamento de um grupo preexistente (ou de suas lideranças) a fim de "esvaziar e conter movimentos atuais ou potenciais de reivindicação de demanda e participação" (Reis, 1977:33). O grupo em questão pode, no limite, submeter-se ao aliciador como um recurso meramente tático, sem perder ou abrir mão de sua identidade original. Transformismo, por sua vez, implica a fabricação "de uma classe dirigente cada vez mais ampla, [...] com a absorção gradual, mas contínua, e obtida com métodos de variada eficácia, dos elementos ativos surgidos dos grupos aliados e mesmo dos adversários e que pareciam irreconciliavelmente inimigos" (Gramsci, 2002:63). Aplicada à elite paulista produzida pelo Estado Novo para governar seu estado natal durante o período, essa formulação ajusta-se quase perfeitamente, como quisemos demonstrar.

O resultado desse artifício político, mais intenso a partir de 1939, pode ser resumido em três etapas.

Há, ao contrário do que se imagina, uma restituição, ainda que incompleta, do poder à elite dirigente do estado - poder este "usurpado" entre 1930 e 1933 pelos tenentes e entre 1937 e 1938 pelos interventores federais ${ }^{24}$.

Essa elite restituída, representada após a extinção dos partidos políticos em 1937 por um pequeno grupo hospedado na interventoria e no departamento administrativo, será responsável pelo apoio político e ideológico emprestado ao ditador e à ditadura - mesmo após o tumulto e os ressentimentos gerados em 1932.

E será justamente essa elite restituída, que compreende ex-membros do PRP, Partido Democrático de São Paulo (PD), PC e Ação Integralista Brasileira (AIB) quem conduzirá o programa de formação dos novos partidos políticos em São Paulo em 1945, especialmente o Partido Trabalhista Brasileiro (PTB) e o Partido Social Democrático (PSD) (Souza, $1976)^{25}$. Esses partidos agora não são mais estaduais, mas nacionais; não mais paulistas, mas "getulistas".

(Recebido para publicação em setembro de 2013)

(Reapresentado em novembro de 2014)

(Aprovado para publicação em janeiro de 2015) 


\section{NOTAS}

1. Para Skidmore, o Estado Novo foi um regime político sem política (1992:61-62).

2. Decreto-Lei 1.202, de 8 de abril de 1939. Ver http://www2.camara.leg.br/legin/ fed / declei / 1930-1939/decreto-lei-1202-8-abril-1939-349366-publicacaooriginal -1-pe.html. Acesso em 12 de agosto de 2013.

3. Para maiores detalhes desse sistema administrativo, ver Codato (2011:321-339).

4. E não um "caso crucial", isto é, um caso único, extraordinário e decisivo para a explicação do problema considerado. Ver Eckstein (1975).

5. Ver, a propósito da falta de trabalhos monográficos sobre o tema, Woodard (2006).

6. Utilizei para as informações discutidas neste artigo um conjunto de evidências compiladas a partir de três tipos de fontes. Arquivos privados: Arquivo do Instituto Histórico e Geográfico de São Paulo; Arquivo Getúlio Vargas (CPDOC / Fundação Getulio Vargas); Arquivo Getúlio Vargas Museu da República - Arquivo Histórico; Arquivo Luís Vergara CPDOC - Fundação Getulio Vargas; Gabinete Civil da Presidência da República. Série: Governos Estaduais. Arquivo Nacional. Jornal diário: $O$ Estado de S. Paulo $(1939,1943,1963)$. Documentos oficiais: Departamento Administrativo do Estado (São Paulo). Pareceres do Conselho Administrativo do Estado de São Paulo. São Paulo, s.c.p., 1939-1947.

7. A expressão designa, de forma pejorativa, os políticos da República Velha (1889-1930) que a Revolução de 1930 - que conduziu Vargas ao poder - derrubou. O significado dicionarizado de "carcomido" é tanto "que se desgastou com o tempo" como "que se deteriorou", e se corrompeu.

8. Portaria n-2 2.083 de 12 de junho de 1939, do Ministério da Justiça e Negócios Interiores.

9. Ver "O Sr. Lafer e sua Nomeação para o Departamento Administrativo". Correio da Manhã, 24 de junho de 1939, p. 14.

10. Ver, para a informação, nota publicada no jornal O Estado de S. Paulo, 9 agosto de 1939, p. 1.

11. Conforme a Ata da $80^{\underline{a}}$ sessão ordinária do Departamento Administrativo do Estado de São Paulo. São Paulo. Departamento Administrativo do Estado. Atas das sessões do Departamento Administrativo do Estado de São Paulo de 1941 (de 25 de março a 29 de julho de 1941). São Paulo, manuscrito, 1941.

12. Dulles especula que a ida de Marcondes Filho para o Ministério do Trabalho foi motivada pelo clima da guerra mundial: "Getúlio, que reconhecia a importância política dos trabalhadores industriais de São Paulo, explicou a Marcondes que o País precisava de um Ministro do Trabalho que conhecesse bem o estado, porque boa parte da força de trabalho paulista era originária dos países do Eixo". Segundo sua opinião Marcondes Filho "tinha poucos traços em comum com os republicanos paulistas conservadores" (Dulles, 1967:241). Essa opinião é completamente injustificada, segundo quaisquer dados disponíveis. Ver, por exemplo, o verbete biográfico de Marcondes Filho no Dicionário Histórico-Biográfico Brasileiro (Abreu et al., 2001).

13. Ver O Estado de S. Paulo, 18 de março de 1945, p. 36; e Reale (1986:188). 


\section{Adriano Codato}

14. Ver, a propósito, Hayashi (1996:122) e Vargas (1995:347, 375 e 393). Ver também Ramalho (1941). João Ramalho era possivelmente o pseudônimo de Epitácio Pessoa Cavalcanti de Albuquerque.

15. Alexandre Marcondes Machado Filho (1892-1974) fazia parte da fina flor da classe política paulista. Graduou-se na Faculdade de Direito de São Paulo em 1914 e tornou-se secretário particular de Bernardino Campos. Tendo sua candidatura o aval de Carlos de Campos, presidente do Estado, foi vereador em São Paulo (1926-1928) pelo Partido Republicano Paulista (PRP) e líder da bancada situacionista na Câmara dos Vereadores de São Paulo (1926). Funda e dirige, em 1927, o São Paulo Jornal, órgão mais popular do Partido Republicano Paulista. Depois disso, foi, por dois mandatos, deputado federal (1927-1929; 1930). Contrário ao movimento de 1930 que depôs Washington Luís, perde o mandato, tem seu periódico empastelado pelos revoltosos, abandona a política e volta a exercer a advocacia até o convite para compor o Departamento Administrativo de São Paulo em 1939. Ver Milliet e Gama Jr. (1927); e Abreu et al. (2001:2083).

16. Em 1939 assumiram seus postos Caetano Munhoz da Rocha (presidente), do Partido Republicano Paranaense (PRPr) e posteriormente da União Republicana Paranaense (URP); Alencar Guimarães, do PRPr e, na República Nova, do Partido Social Nacionalista (PSN); Roberto Glaser (vice-presidente, depois presidente), do PRPr e do PSN; e Epaminondas Santos. Essa bancada oposicionista foi, logo no segundo ano, trocada por dois políticos do partido do interventor (o efêmero Partido Social Democrático pré-1937): Carvalho Chaves substitui Munhoz da Rocha e Caio Machado, o ex-senador Alencar Guimarães, mas o presidente do departamento administrativo do Paraná continuará sendo um político não alinhado a Manoel Ribas (Glaser). Em 1942, Flávio Guimarães, aparentado do interventor, assume a vaga deixada por Caio Machado. Para essas várias sucessões, ver (Paraná. Departamento Administrativo do Estado do Paraná); diversos anos. Para as filiações partidárias e o parentesco, ver Costa (1992) e Tourinho (1991).

17. Alcides Gonçalves de Souza (o primeiro presidente do Departamento Administrativo mineiro) seria secretário da Agricultura, Indústria, Comércio e Trabalho do governo Benedito Valadares em 1942-1943; Domingos Henriques de Gusmão Jr. foi chefe de Polícia do estado de Minas Gerais (1935) e, posteriormente, secretário do Interior e Comandante da Força Pública (1936). Raul Noronha de Sá foi secretário estadual de Viação e Obras Públicas do governo Valadares (1935-1937). Nestor Fóscolo foi destacado deputado estadual constituinte (1935-1937) pelo partido do governador, o Partido Progressista de Minas Gerais (PP) e Álvaro Baptista de Oliveira, substituto do interventor Gustavo Capanema (também presidente do DAE-MG), foi ministro do Tribunal de Contas de Minas Gerais antes e depois de sua passagem pelo Departamento. Essa a bancada governista. Não alinhados ao interventor: José Martins Prates (vice-presidente), político de Teófilo Otoni, foi deputado estadual constituinte (1935-1937) pelo PP, mas era ligado a Bernardes; e Francisco de Salles Oliveira, vereador com base em Juiz de Fora, pertenceu ao PSD "independente" e apoiou Mílton Campos ao governo de Minas em 1946. As informações sobre as trajetórias dos políticos mineiros são de Monteiro (1994).

18. Utilizo a noção de "fórmula política" tanto no sentido consagrado por Mosca - isto é, um princípio moral e legal em que se assenta "o poder" e a justificação desse poder "da classe política em todas as sociedades", ideia essa designada mais frequente- 
mente como "ideologia" - quanto num sentido mais amplo: o autoritarismo é, nesse período, além de uma "ideologia", uma fórmula, um método (um modo de proceder) de divisão do poder entre os grupos de elite que exige e impõe um dado arranjo institucional. Ver Mosca (1939:70).

19. O art. 73 reza textualmente: “O Presidente da República, autoridade suprema do Estado, coordena a atividade dos órgãos representativos, de grau superior, dirige a política interna e externa, promove ou orienta a política legislativa de interesse nacional, e superintende a administração do País". Disponível em http: / / www.planalto.gov.br/ccivil_03/constituicao/constitui\%C3\%A7ao37.htm. Acesso em 14/8/2013.

20. Para uma formulação aparentada a essa, veja Cunha (1963:89-90).

21. Ver Administração dos estados e municípios. O Estado de S. Paulo, 4 de julho de 1939, p. 1. Por longos meses, contudo, Lins esteve afastado das atividades do departamento por motivo de doença.

22. Esse jogo de alianças intraelite era muito dinâmico e a capacidade de aliciamento do interventor não deve ser subestimada. Antonio Gontijo, uma figura politicamente apagada no PRP, deveu certamente sua nomeação à proximidade com a ala velha. Contudo, "durante os primeiros anos da década de 1940, Ademar foi suspeito de estar ligado a um movimento de conspiração ideológica contra o governo federal. [...] As suspeitas surgidas em 1942" relatavam que integrariam a "rede de conspiração" Armando de Sales e Antonio Gontijo (Moraes, 2002:75). A referência do documento citado é: DEOPS/SP, DAESP. Dossiê 20-F-1, 75. 08/05/1942.

23. Baseei a coloração política de cada um dos integrantes do departamento administrativo do estado de São Paulo em dois documentos: no comunicado secreto do serviço de informações do governo Vargas (produzido em meados de 1942), em que se relata uma possível conspiração política, sob os olhos de Fernando Costa, para reconduzir Ademar ao poder e a participação destacada de Cirilo Júnior no levantamento e administração de fundos para a tal campanha (ver Arquivo Getúlio Vargas GV 42.08.17 CPDOC/FGV); e na cópia de carta procedente de Buenos Aires, datada de 11 de junho de 1941, escrita por Luiz de Toledo Piza Sobrinho e endereçada a sua esposa, Rejana Piza, interceptada e transcrita pelo serviço de informação do governo. Ver Arquivo Getúlio Vargas GV 41.06.11/7 CPDOC/FGV.

24. Para essa história, ver Codato (2010).

25. Para uma análise geral do perfil dos políticos do PSD e da UDN e suas respectivas bases sociais, além de algumas breves observações sobre as peculiaridades de São Paulo, ver Miceli (1991). Para a história da convenção de instalação do PSD em São Paulo e a lista do diretório estadual, ver Valadares (1966:255-258). 


\section{Adriano Codato}

\section{REFERÊNCIAS BIBLIOGRÁFICAS}

ABREU, Alzira Alves de et al. (eds.). (2001), Dicionário Histórico-Biográfico Brasileiro. Rio de Janeiro, Centro de Pesquisa e Documentação de História Contemporânea do Brasil/FGV.

ABREU, Luciano Aronne. (2007), Um Olhar Regional sobre o Estado Novo. Porto Alegre, EDIPUCRS.

AMARAL, Azevedo. (1938), Estado Autoritário e a Realidade Nacional. Rio de Janeiro, José Olympio.

(1943), "Realismo Político e Democracia", in A. de Andrade (ed.), O Pensamento Político do Presidente. Separata de Artigos e Editoriais dos Primeiros 25 Números da Revista "Cultura Política" Comemorativa do 60 Aniversário do Presidente Getúlio Vargas. Rio de Janeiro, Imprensa Nacional.

BOURDIEU, Pierre. (2005), “Da Casa do Rei à Razão de Estado: Um Modelo da Gênese do Campo Burocrático", in L. Wacquant (ed.), O Mistério do Ministério. Pierre Bourdieu e a Política Democrática. Rio de Janeiro, Revan.

CAMARGO, Aspásia. (1983), “A Revolução das Elites: Conflitos Regionais e Centralização Política" , in CPDOC / FGV (ed.), A Revolução de 1930: Seminário Internacional. Brasília, Editora UnB.

CAMARGO, Dilan D’Ornellas. (1983), Centralização e Intervenção: Padrão Político e Institucional do Estado Novo no Rio Grande do Sul - O Departamento Administrativo de Estado - RS. Dissertação de Mestrado, Universidade Federal do Rio Grande do Sul. Porto Alegre, RS.

CAMPOS, Francisco. (1940a), O Estado Nacional: Sua Estrutura; seu Conteúdo Ideológico. Rio de Janeiro, José Olympio.

(1940b), "O Estado Nacional”, in O Estado Nacional: Sua Estrutura; seu Conteúdo Ideológico. Rio de Janeiro, José Olympio.

CARONE, Edgard. (1976), O Estado Novo (1937-1945). São Paulo, Difel.

CODATO, Adriano. (2010), “A Elite Destituída: A Classe Política Paulista nos Anos Trinta", in J. R. C. Caldeira e N. Odalia (eds.), História do Estado de São Paulo: A Formação da Unidade Paulista. São Paulo, Editora Unesp/Imprensa Oficial/ Arquivo Público do Estado, pp. 275-305.

. (2011), "Intervenção Estatal, Centralização Política e Reforma Burocrática: O Significado dos Departamentos Administrativos no Estado Novo". Revista do Serviço Público, vol. 62, no 3, pp. 321-339.

. (2013), “Os Mecanismos Institucionais da Ditadura de 1937: Uma Análise das Contradições do Regime de Interventorias Federais nos Estados". História (São Paulo), vol. 32, no 2, pp.189-208.

COSTA, Samuel Guimarães da. (1992), História Política da Assembleia Legislativa do Paraná. Curitiba, Assembleia Legislativa.

COUTINHO, Lourival. (1955), O General Góes Depõe... Rio de Janeiro, Livraria Editora Coelho Branco. 
CUNHA, Mário Wagner Vieira da. (1963), O Sistema Administrativo Brasileiro (1930-1950). Rio de Janeiro, Instituto Nacional de Estudos Pedagógicos.

DANTAS, José Ibarê Costa. (1982), As Políticas das Interventorias em Sergipe (1930-1945). Dissertação de Mestrado, Universidade Estadual de Campinas. Campinas, SP.

DULLES, John W. F. (1967), Getúlio Vargas: Biografia Política (2a ed.). Rio de Janeiro, Renes.

ECKSTEIN, Harry. (1975), "Case Study and Theory in Political Science”, in F. I. Greenstein e N. Polsby (eds.), Handbook of Political Science. Readding, Addison-Wesley. Vol. 7, pp. 79-137.

FRISCHAUER, Paul. (1943), Presidente Vargas. São Paulo, Companhia Editora Nacional.

GRAHAM, Lawrence S. (1968), Civil Service Reform in Brazil: Principles versus Practice. Austin, University of Texas Press.

GRAMSCI, Antonio. (2002), Cadernos do Cárcere. Rio de Janeiro, Civilização Brasileira. Vol. 5.

HAYASHI, Marli Guimarães. (1996), A Gênese do Ademarismo (1938-1941). Dissertação de Mestrado, Universidade de São Paulo. São Paulo.

LOWENSTEIN, Karl. (1944), Brazil under Vargas. New York, The Macmillan Company.

MICELI, Sergio. (1991), “Carne e Osso da Elite Política Brasileira Pós-1930”, in B. Fausto e S. B. de Holanda (orgs.), História Geral da Civilização Brasileira (5a ed.). Rio de Janeiro, Bertrand Brasil. Vol. 3, pp. 557-596.

. (2001), "Intelectuais e Classe Dirigente no Brasil (1930-45)", in Intelectuais à Brasileira. São Paulo, Companhia das Letras, pp. 69-291.

MILLIET, Gustavo e GAMA JR., F. I. (eds.). (1927), Annaes da Câmara Municipal de São Paulo: 1926 (1․ Anno da 12a Legislatura). São Paulo, Ferrari \& Losasso.

MONTEIRO, Norma de Góes (ed.). (1994), Dicionário Biográfico de Minas Gerais: Período Republicano (1889/1991). Belo Horizonte, Assembleia Legislativa do Estado de Minas Gerais.

MORAES, Maria Blassioli. (2002), "Adhemar de Barros, o Líder Populista e a Política Nacional através do DEOPS”, in M. A. Aquino et al. (eds.), A Constância do Olhar Vigilante: A Preocupação com o Crime Político. São Paulo, Arquivo do Estado; Imprensa Oficial.

MOSCA, Gaetano. (1939), The Ruling Class (Elementi di Scienza Politica). New York, McGraw-Hill.

PARANÁ. Departamento Administrativo do Estado do Paraná (vários anos), Atas das Sessões do Departamento Administrativo do Paraná. Manuscrito.

PUTNAM, Robert D. (1976), The Comparative Study of Political Elites. Englewood Cliffs, NJ, Prentice Hall.

RAMALHO, João. (1941), A Administração Calamitosa do Sr. Adhemar de Barros em São Paulo. Rio de Janeiro, Editora A de Barros.

REALE, Miguel. (1986), Memórias: Destinos Cruzados. São Paulo, Saraiva. Vol. 1.

DADOS - Revista de Ciências Sociais, Rio de Janeiro, vol. 58, nํ 2, 2015 


\section{Adriano Codato}

REIS, Fábio Wanderley. (1977), "As Eleições e o Problema Institucional (2): A Revolução é a Geral Cooptação". DADOS - Revista de Ciências Sociais, no 14, pp. 185-200.

SKIDMORE, Thomas E. (1992), Brasil: De Getúlio Vargas a Castelo Branco, 1930-1964 (10a ed.). Rio de Janeiro, Paz e Terra.

SOUZA, Maria do Carmo Campello de. (1976), Estado e Partidos Políticos no Brasil (1930-1964). São Paulo, Alfa-Ômega.

TOURINHO, Luiz Carlos Pereira. (1991), Toiro Passante. Curitiba, Lítero-Técnica. Vol. IV.

VALADARES, Benedito. (1966), Tempos Idos e Vividos: Memórias. Rio de Janeiro, Civilização Brasileira.

VARGAS, Getúlio. (1938), “Proclamação ao Povo Brasileiro ('À Nação'). Lida no Palácio Guanabara e Irradiada para todo o País na Noite de 10 de novembro de 1937)", in A Nova Política do Brasil. Rio de Janeiro, José Olympio. Vol. V.

. (1995), Getúlio Vargas: Diário. São Paulo, Siciliano; Rio de Janeiro, Editora FGV. Vol. II.

VIANNA, Oliveira. (1974), Problemas de Política Objetiva (3a ed.). Rio de Janeiro, Record.

WEBER, Max. (1994), "The Profession and Vocation of Politics", in P. Lassman e R. Speirs (eds.), Weber: Political Writings. Cambridge, Cambridge University Press, pp. 309-369.

WOODARD, James P. (2006), "'All for São Paulo, all for Brazil': Vargas, the Paulistas, and the Historiography of Twentieth-Century Brazil", in J. R. Hentschke (ed.), Vargas and Brazil: New Perspectives. London, Palgrave Macmillan, pp. 83-107. 


\section{RESUMO}

Estado Novo no Brasil: Um Estudo da Dinâmica das Elites Políticas Regionais em Contexto Autoritário

Este artigo reconstrói a lógica de reconstituição da classe política estadual durante o Estado Novo no Brasil. Expomos os mecanismos de formação de apoios por parte da elite nacional, os princípios que guiaram as relações entre a elite regional e a cúpula dos Executivos estadual e federal e, especificamente, o modo pelo qual o presidente da República exerceu suas prerrogativas autoritárias diante das classes dirigentes regionais. É privilegiado o caso de São Paulo, mas as situações políticas de Minas Gerais, Rio Grande do Sul e Paraná são também comentadas. Foram propostas duas noções para explicar esse processo: "geometria variável" e "personalismo institucionalizado". Como conclusão, contesta-se a ideia segundo a qual a política seletiva de conservação/ renovação das classes dirigentes estaduais deva ser descrita como cooptação de elites. O mais apropriado seria a noção de transformismo político, que implica na fabricação de uma nova classe dirigente através da destituição seletiva do grupo inimigo por uma elite mais poderosa.

Palavras-chave: elite política; política brasileira; Getúlio Vargas; Estado Novo; circulação de elites

\section{ABSTRACT \\ The New State in Brazil: A Study of the Dynamics of Regional Political Elites in an Authoritarian Context}

This article reconstructs the logic of the reconstitution of the state-level political class during the "New State" period in Brazil. The author depict the mechanisms of political support formation by the national elite as well as the principles that guided the relationship between the regional elite and the higher echelons of the state and federal executive branches and, specifically, how the president of the Republic exercised his authoritarian prerogatives towards the regional decision-taking classes. The case of São Paulo is granted particular attention, but the political situations in Minas Gerais, Rio Grande do Sul and Paraná are also approached. Two notions are advanced in order to understand this process: "variable geometry" and "institutionalized personalism". As a conclusion, the article challenges the idea according to which the selective politics of the conservation/renovation of directing classes must be inscribed within the cooptation of elites. The notion of political transformism is deemed more appropriate, entailing in the fabrication of a new ruling class through the selective destitution of the enemy group by the more powerful elite.

Keywords: political elites; Brazilian politics; Getúlio Vargas; New State; circulation of elites 


\section{Adriano Codato}

\section{RÉSUMÉ}

L'État Nouveau au Brésil: Une Étude de la Dynamique des Élites Politiques Régionales en Contexte Autoritaire

Cet article analyse la logique de rénovation de la classe politique des différents États de la fédération brésilienne à l'époque de "l'État Nouveau". Nous y exposerons les mécanismes de configuration des soutiens apportés par l'élite nationale, les principes ayant orienté les relations entre l'élite régionale et les plus hautes sphères des pouvoirs exécutifs d'État et fédéral, et plus spécifiquement la manière dont le président de la République a exercé ses prérogatives autoritaires face aux classes dirigeantes régionales. Nous privilégierons ici le cas de l'État de São Paulo, sans pour autant négliger les différentes conjonctures politiques de Minas Gerais, du Rio Grande do Sul et du Paraná. Deux notions sont ici proposées pour expliquer ces processus: "géométrie variable" et "personnalisme institutionnalisé". Nous conclurons par la contestation de l'idée selon laquelle la politique sélective de conservation/rénovation des classes dirigeantes des différents États doit être décrite comme un processus de cooptation des élites. Il semble plus approprié d'avancer la notion de transformisme politique, qui implique la constitution d'une nouvelle classe dirigeante à travers la destitution sélective du groupe adverse par une élite plus puissante.

Mots-clés: élite politique; politique brésilienne; Getúlio Vargas; État Nouveau; circulation des élites

\section{RESUMEN}

\section{El Estado Nuevo en Brasil: Un Estudio de la Dinámica de las Elites Politicas Regionales en un Contexto Autoritario}

Este artículo reconstruye la lógica de reconstitución de la clase política estatal durante el Estado Nuevo en Brasil. Exponemos los mecanismos de formación de apoyos por parte de la elite nacional, los principios que guiaron las relaciones entre la elite regional y la cumbre de los Ejecutivos a nivel estatal y federal y, particularmente, el modelo por el cual el presidente de la República ejerció sus prerrogativas autoritarias frente a las clases dirigentes regionales. Se privilegia el caso de São Paulo, aunque también se comentan algunas situaciones políticas de Minas Gerais, Rio Grande del Sur y Paraná. Dos nociones son propuestas para explicar este proceso: "geometría variable" y "personalismo institucionalizado". A modo de conclusión, se contesta la idea según la cual la política selectiva de conservación/renovación de las clases dirigentes estatales debe ser descrita como cooptación de elites. Lo más apropiado sería la noción de transformismo político, que implica la generación de una nueva clase dirigente a través de la destitución selectiva del grupo enemigo por una elite más poderosa.

Palabras clave: elite política; política brasileña; Getúlio Vargas; Estado Nuevo; circulación de elites 